\title{
Cléber Bidegain Pereira
}

Temos a honra de apresentar, nesta edição, o consultor da Revista Dental Press de Ortodontia e Ortopedia Facial, Cléber Bidegain Pereira. Podemos considerar sem dúvida o Dr. Cléber como um homem à frente de seu tempo. Dedicado e determinado sobre o trabalho que realiza, sempre antecipou-se no uso das tecnologias e inovações que surgem na Ortodontia, testando-as, analisando-as e, o mais importante de tudo, transmitindo os conhecimentos adquiridos de forma benévola, imparcial e apaixonante. Suas experiências com os índios Yanomamis, no início da década de 70, tornaram-se referenciais para o mapeamento da saúde bucal nos diversos rincões do país, além da contribuição para a pesquisa. Pioneiro na introdução da Informática na Ortodontia, o Dr. Cléber fala-nos sobre as mudanças que o dia-a-dia do consultório pode sofrer com a tecnologia e com a presença do computador, sobre certificação digital e sobre como manter a paixão pela Ortodontia após tantos anos de profissão.

Adilson Luiz Ramos

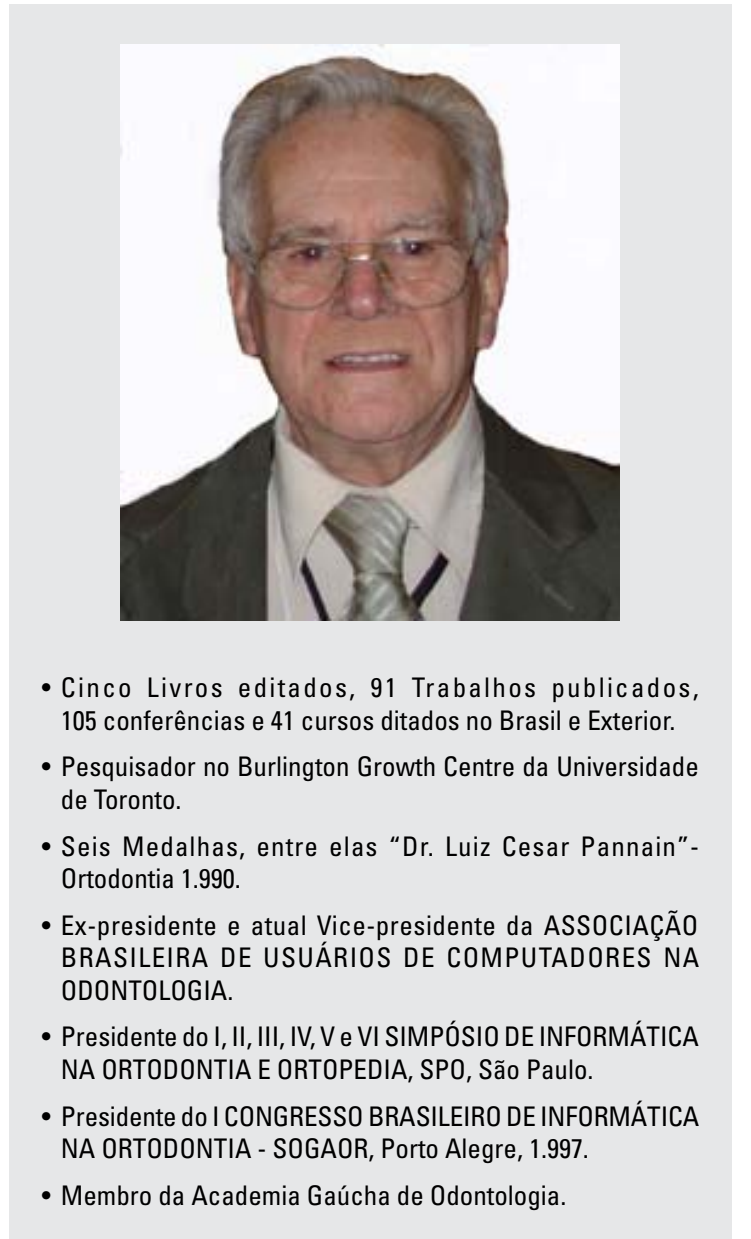

1) Dr. Cléber, o que o Sr. poderia nos informar sobre a atual legislação e procedimentos quanto à legalidade das imagens digitais? Adilson Luiz Ramos

A Legislação vigente é muito clara e determinante. Pela Medida Provisória 2200-2, de 24 de agosto de 2001, foram criadas as Autoridades Certificadoras, que estão credenciadas para emitir Certificados Digitais, os quais correspondem à Carteira de Identidade eletrônica do indivíduo. Com este Certificado, de baixo custo e validade de dois anos, pode-se assinar arquivos digitais, em qualquer formato e em qualquer quantidade, dentro da validade do Certificado. Este procedimento confere ao arquivo digital inquestionável legalidade, tendo o mesmo valor jurídico que documentos em papel com assinatura reconhecida em Cartório. Isto é, tem maior valor do que papéis assinados sem reconhecimento de firma. É oportuno comentar que os Três Poderes da República estão migrando rapidamente para o digital, exigindo, em muitos casos, do público, empresas e instituições que todos os trâmites sejam em digital, com Certificado. Um dos muitos exemplos: o MEC só aceita inscrições para bolsas pela internet com assinatura digital (http://www.mec.gov.br/prouni/Digital.asp). 
O Conselho da Justiça Federal (CJF), o Superior Tribunal de Justiça (STJ) e os Tribunais Regionais Federais, consideram tão importante a Certificação Digital que tem sua própria Autoridade Certificadora, a fim de emitir Certificados para seu grupo jurídico e funcionários (www.iti.gov.br - Notícia 17 dezembro 2004).

Mais informações sobre como adquirir o Certificado em:

http://www.cleber.com.br/smart2.html

2) Diante do seu conhecimento em captação de imagens digitais, quais seriam as dicas para o ortodontista que irá comprar a sua primeira câmera digital hoje? Adilson Luiz Ramos

Gostei do termo "dicas", que para mim são conselhos atenuados, sugestões...

A) Todas as grandes marcas internacionais estão na internet, oferecendo múltiplos modelos de câmaras digitais. As topo-de-linha oferecem sempre alguma vantagem a mais. Mas, são bem mais caras... Pode-se conseguir uma boa câmara, que já saiu de produção, por bom preço nas lojas do ramo ou na internet. Inclusive no Mercado Livre de usados.

B) Câmara fora de linha, já no rol das velhas, como a minha amada Sony DCS -770C, cumpre bem as necessidades que existem na Ortodontia. Para projeção em telão ou para ampliações em positivo de tamanho $18 \times 24 \mathrm{~cm}$ ela oferece resolução mais que suficiente. Quem pode comprar um modelo mais avançado, melhor... Mas quem ficar neste patamar estará bem servido...

C) As câmaras digitais atuais estão super desenvolvidas em seu sistema eletrônico e, como este pode ser reproduzido com facilidade, quase todas as máquinas têm excelentes recursos digitais. A preocupação é o sistema ótico. Em matéria de lente, tamanho é documento sim.... Lentes grandes têm maior potencialidade. Lentes de cristal de marca reconhecida inspiram maior confiança e, geralmente, são melhores.

D) Tenha duas câmaras, uma social e outra profissional. A social pode ser qualquer uma das centenas que são oferecidas por aí. Se não há intenção de fazer positivos de tamanho grande, pode até ter lente de plástico... São mais portáteis e em caso de perda não se morre de desgosto... A câmara profissional, de maior tamanho e lente melhor para close, deve ficar sempre no consultório, com as configurações para este mister.

E) A iluminação é fundamental. O flash acoplado da máquina é inadequado para as fotografias odontológicas. Seguindo uma tendência dos EUA, abandonei o flash circular, depois de usá-lo por 40 anos.... Ele achata a imagem eliminando as sombras que são necessárias para a fotografia. Prefiro uma luminária, não presa na câmara e sim direcionada por uma auxiliar, segundo a necessidade dos locais a serem iluminados.

F) Se optar por duas câmaras, compre da mesma marca, assim pode compartilhar os complementos.

G) Igual como ama as pessoas, os pássaros e as estrelas, ame seu equipamento, tirando o melhor proveito dele.

Mais informações sobre câmaras digitais:

http://www.cleber.com.br/novascam.html

3) Depois de uma vasta experiência clínica em Ortodontia e os estudos que o Sr. fez a partir da amostra de crescimento de Burlington, quais seriam as suas principais observações relacionadas a este tema (crescimento e cefalometria)? Adilson Luiz Ramos

Mesmo com todas suas imperfeições, a cefalometria é uma ferramenta maravilhosa que dispomos para avaliar o crescimento e a estrutura facial de nossos pacientes. $\mathrm{O}$ acervo que a ciência acumulou de informações vindas da cefalometria é extremamente valioso e, ancorada nele, a Ortodontia tomou maior consistência cientifica abandonando o abstrato e aproximando-se do concreto. Em pesquisas de crescimento, os estudos transversais geralmente não são totalmente satisfatórios. É difícil, quase impossível, reunir um material relativamente homogêneo que possa ser representativo de determinado grupo. Os estudos longitudinais são o ideal. E, no meu conhecimento, o estudo do Burlington Growth Centre, 
da Universidade de Toronto, é o mais rico e numeroso. Ainda há muito o que estudar em cima deste fantástico material que documentou, anualmente, o crescimentos de 1.200 crianças dos 3 aos 20 anos. O material do qual sou depositário compreende: 45 casos de oclusão normal, sem tratamento, com cefalogramas lateral e frontal aos 3, 6, 9, 12 e 20 anos. Ele está à disposição da comunidade científica. Se alguém sabe que me conte, mas eu desconheço os verdadeiros mecanismos bio-químicos que regem o crescimento. Assim, a cefalometria é a melhor informação que dispomos para acompanhar o crescimento e, baseado no comportamento de casos similares de estudos longitudinais, fazer a previsão para o crescimento do paciente. É uma previsão estatística, com segurança relativa. Uma das ocorrências importantes que encontrei no material do Burlington que estudei, foi que o ângulo SNA diminui, significativamente, nas idades de 9-12 anos. Ocorre que, nestes casos, o Nasion cresce horizontalmente mais do que o ponto A, diminuindo o SNA.

Mais informações sobre o Estudo de Burlington:

http://www.cleber.com.br/anguloanb.html

http://www.cleber.com.br/plastici.html

http://www.cleber.com.br/burlin.html

\section{4) Numa era de retomada do uso da análise facial em detrimento da cefalometria, quais as suas ressalvas quanto ao planejamento orto- dôntico para quem pretende descartar a avalia- ção cefalométrica clássica? Adilson Luiz Ramos}

A análise facial sempre foi e será o principal elemento de nossas avaliações. A cefalometria com toda a carga de informações acumulada nas pesquisas, desde 1931, será também, sempre, um importante elemento complementar de avaliação. A cefalometria em $3 \mathrm{D}$ e a prototipagem abrem um novo horizonte no estudo da estrutura da face. Porém, quem descartar a cefalometria clássica perderá um valioso conjunto de informações para o planejamento e avalição de resultados. A boa notícia é que a tomografia da hemi-face oferece tudo o que sonhamos para a cefalometria. Uma imagem limpa, sem sobreposi- ções, tornando possivel a marcação de pontos laterais com segurança, inclusive possibilitando a marcação de pontos pelo computador. Assim a cefalometria em 2D, gerada da 3D, voltaria com mais força e confiabilidade nos pontos cefalométricos laterais. E não estaria perdido todo o acervo conquistado nestes 73 anos de cefalometria (www.orto2004.com.br/tomogra2.html).

5) $O$ que o Sr., como um ortodontista sempre pioneiro e visionário, à frente das novas tecnologias, vislumbra para o futuro de nossa profissão? Adilson Luiz Ramos

Igual a todas as outras atividades humanas, a Odontologia terá como suporte a Informática. Mas as grandes revoluções virão da Engenharia Genética.

Se pensarmos que as discrepâncias esqueléticas, em sua grande maioria, são genéticas. E considerarmos os fantásticos avanços que acontecem na Engenharia Genética, nas possibilidades que se abrem com a descoberta dos códigos genéticos, o aproveitamento das células troncos.... Vamos concluir que os tratamentos ortodônticos do futuro serão feitos nos laboratórios de genética.... O ortodontista, ao invés de alicates usará o microscópio.

6) Como e quando começou o seu interesse, quase paixão pela computação aplicada à Ortodontia e Ortopedia Facial? Kurt Faltin Jr.

Em 1979, na minha primeira investida na Universidade de Toronto, a esposa do meu orientador me disse: se tirar o computador do Mayhall ele morre... Fiquei fascinado e de chegada comprei meu primeiro CP-500. Era uma "maravilha", imaginem que tinha como memória um disquete de $180 \mathrm{~KB}$ ??? Que depois se podia ler dos dois lados e tínhamos $360 \mathrm{~KB}$ de memória... Um assombro. HD nem sabia que existia... Foi paixão mesmo, daquelas em que só se enxergam as belezas.... Aliás, meu querido amigo Kurt, dentre minhas poucas virtudes ou muitos defeitos... está colocar paixão desenfreada nas coisas que faço. Em 1984 com um grupo de valorosos companheiros fundamos a Ass. Brasileira de Usuários de 
Computadores na Odontologia (ABUCO). O ideal e a amizade do grupo permanece até hoje.

7) Você tem conhecimento de pesquisas feitas com o objetivo de comparar os resultados obtidos por programas cefalométricos computadorizados e sua exatidão ou confiabilidade? Kurt Faltin Jr.

A exatidão dos programas cefalométricos computadorizados vem sendo comprovada em diversas pesquisas, internacionais e nacionais. Entre nós, ressalta o trabalho de Brangeli ${ }^{1}$ e os exaustivos e sábios trabalhos sobre erro em cefalometria da Unesp (Araraquara), de início, liderados por nosso saudoso amigo Joel da Costa Martin, depois por Ary dos Santos Pinto e outros. Inclusive foram testados os dois sistemas de marcação de pontos, na tela do computador ou na Mesa Digitalizadora, ambos os sistemas mostram ser altamente confiáveis. O erro, quando presente, é do operador e igual no sistema clássico. Como eu tenho um pouco de São Tomé, também fiz minhas comprovações "caseiras"... Fiquei deslumbrado com a coincidência das formas. Os números até podem variar por outros fatores, inclusive pela espessura dos marcadores, digital $(0.2 \mathrm{~mm}$ ) Lápis não constante.... Nada que comprometa o diagnóstico.

Relação de alguns trabalhos sobre erro em cefalometria:

http://www.cleber.com.br/errocefalo.html

8) Será que algum dia poderemos unificar as análises cefalométricas computadorizadas para, num "linguajar comum", podermos realmente comparar diagnóstico e resultados? Kurt Faltin Jr.

Este "linguajar comum" como muito bem te expressas não foi conseguido com o Esperanto... difícil que seja conseguido entre os autores e nem mesmo entre os programadores. De qualquer maneira a cefalometria Computadorizada deu um passo no

1. BRANGELI, L.A.M.; HENRIQUES, J.F.C.; VASCONCELOS, M.H.F.; JANSON G.R.P. Estudo comparativo da análise cefalométrica pelo método manual e computadorizado. Rev Assoc Paul Cir Dent, v.54, n.3, p. 234, maio- 2000. sentido de que os programas geram todas as análises. A respeito, eu sonhei um dia que se deveria fazer ao contrário. Separar as análises em módulos para gerar apenas uma análise, possibilitando a escolha, do profissional, da análise de sua preferência. Assim, não se teria de marcar pontos de outras análises, às vezes estranhas ao seu cotidiano. A idéia não proliferou pois os traçados já não mais são feitos pelo profissional (salvo honrosas exceções) e sim pelos Serviços de Radiologias e estes querem ter todas as análises... Também os programas são feitos para Serviços de Radiologia, não para clínicos... $\mathrm{O}$ individualismo cede lugar à massificação... Comparar diagnóstico e resultados são mais facilmente conseguidos graças à cefalometria Computadorizada que, ao oferecer múltiplas análises possibilita ao profissional escolher a mesma análise no antes e depois.

\section{9) Os arquivos eletrônicos já podem ser con-} siderados documentos oficiais sem muita burocracia e despesas? Como? Kurt Faltin Jr.

Com a mais absoluta segurança os arquivos digitais têm validade jurídica e maior credibilidade científica, quando assinados eletronicamente com Certificado Digital padrão ICP-Brasil. A burocracia e as despesas são mínimas. A ninguém ocorre imprimir, em papel, uma receita ou outro documento e não assiná-lo, seria apócrifo. É o mesmo com o digital, ele carece de assinatura eletrônica e agora ela existe legalmente. Como? É necessário adquirir um Certificado Digital, que custa em torno de 100 reais e tem validade de 2 anos, sem limites para o número de documentos assinados dentro de seu prazo de validade. Também é necessário um implemento para armazenar este Certificado e senha. Um destes implementos USB - token - custa em redor de R $\$ 140.00$ (Na renovação do Certificado é utilizado o mesmo token). Igual a uma carteira de identidade ou passaporte, a emissão é presencial e deve ser adquirida em Autoridade Certificadora (credenciada pelo governo), Padrão ICP-Brasil, conforme recomendação dos Fóruns CRO/RS (2003), CRO/GO (2003), CRO/ SP (2004) e Simpósio Certificação ORTO2004. 
Com o auxílio de um programa gratuito (X Sing ou outros) insere-se a assinatura no arquivo, danto-lhe identidade e invulnerabilidade garantida pela legislação atual. Há outras mídias de armazenamento mais baratas, como o smart card e estuda-se outras ainda mais baratas... A Dra. Nayene L.M. Eid realizou, no pré Orto2004, um trabalho estimulando os programadores da Odontologia para que inserissem estas ferramentas. De meu conhecimento, nos dias de hoje, já existem quatro programas, específicos da Odontologia, que têm as ferramentas para inserir a assinatura e criptografar documentos. Dos genéricos, com ferramentas para certificação, está o Outlook.

10) Considerando seus esforços e experiência na aplicação da Informática à Odontologia, quais são seus conselhos para quem está se preparando para incorporar o uso de computadores na rotina do consultório? Ricardo Nakama

Que não espere mais, que mergulhe imediatamente na Informática. Quanto mais passa o tempo mais difícil, para ele, será integrar-se nesta tecnologia. Não mais se podem ignorar os computadores, os quais penetraram profundamente em todas as atividades humanas. A Informática, cada vez mais, serve de suporte para as atividades clínicas da Odontologia, como acontece em todas as outras atividades.

11) Tornar nossos consultórios mais competitivos é uma das vantagens proporcionadas pelo desenvolvimento tecnológico. Como adepto e grande usuário de novidades tecnológicas, o senhor poderia compartilhar sua melhor experiência com a aplicação de tecnologias em relação ao aumento de qualidade no atendimento dos seus clientes? Ricardo Nakama

Eu vejo as coisas assim. Antes, os pacientes entravam nos nossos consultórios e pensavam: este profissional é avançado... Até computador ele tem... Hoje, não encontrando o computador no consultório de seu odontólogo o paciente pensa: este profissional é bom, porque tenho excelentes informações dele, certamente deve ter o seu computador em casa, pois ninguém hoje pode estudar e pesquisar sem estar ligado na rede...Quase tudo está disponibilizado na rede, informações de várias naturezas, serviços e, principalmente, bibliotecas onde podemos saciar nossa sede de aprendizado. Vivo em uma cidade pequena, em anos passados, muitas vezes viajei para ficar sentado, lendo, nas bibliotecas. Quando veio o xerox foi um "salva a pátria..." Agora todos fazemos pesquisa sem sair de casa.... Só isto já é motivo suficiente para dar graças à tecnologia? Mas, confesso, minha melhor experiência tem sido com as imagens. Tenho minhas primeiras imagens digitais feitas em 1992.

Tocando direto no nosso bolso, tenho uma experiência muito prazerosa com a emissão de carnês para os pagamentos parcelados. Seguramente faz coisa de 20 anos que emito carnês, foi no tempo do CP-500 que iniciei, aproveitando a idéia de Antônio R. de Almeida, meu "guru" em todas as áreas do conhecimento. Tenho também uma máquina de autenticar documentos, sucata de sistema antigo do BB. O paciente está condicionado para pagar carnês. Isto faz parte de sua vida. Antes, quando eu viajava, ao chegar encontrava o caixa vazio... Ninguém pagava.... O cliente chegava para pagar e perguntava: o doutor está? Quando não, ele ia embora sem pagar... Agora, o paciente paga com o carnê e tem a comprovação autenticada igual à de outros carnês.

12) Digamos que no planejamento de montagem de um novo consultório haja limitações orçamentárias e tenhamos que priorizar os investimentos inicias. Qual seria a prioridade de investimento em tecnologia, e quais os benefícios esperados dessa aplicação? Ricardo Nakama

O ultra-som e o laser são ferramentas que vem se impondo em algumas especialidades da Odontologia. No que se refere à Ortodontia e Ortopedia, a prioridade é um computador, com plataforma mínima que possa navegar na internet e que possa visualizar imagens. Não necessariamente deve ser um poderoso computador. Você pode "herdar" o computador do seu filho. Quando seu filho the 
disser: "pai não dá prá agüentá esta minha máquina, é muito lenta, tem pouca memória e sua placa de vídeo não serve para os joguinhos avançados que meus amigos têm"... Então você compra outro computador para ele e fica com o dele que lhe servirá muito bem, pelo menos de início, até chegar a níveis mais altos...Segunda prioridade: uma câmara fotográfica digital. Não precisa ser uma super câmara, apenas o suficiente para que permita documentar seus casos, com fotos intrabucais e da face. O antes e depois pode ser feito nos Serviços de Documentação, mas o trans-tratamento deverá ser feito por nós mesmos. Fotografar a evolução do tratamento é uma fonte de aprendizado e estímulo para o profissional e paciente. Eu continuo um aprendiz de Ortodontia - em casa, revejo as fotografias do dia e, algumas vezes, observo detalhes que me haviam passado desapercebidos... Nestes 50 anos de fotografias ortodônticas tenho apreendido muito vendo e revendo imagens. Em minhas fotografias de anos passados aprendo na escola da vida. É quase como se tivesse uma bola de cristal... Não é possível guardar modelos por toda uma vida.... Imagens sim. $\mathrm{E}$ imagens digitais mais fácil ainda... (http://www.cleber.com.br/50depois. html). Mandar fotos trans-tratamento, via internet, para o paciente fotografado, e para o clínico que nos recomendou este paciente, é uma poderosa maneira de mostrar o que estamos fazendo. Minha amada mãe me ensinou: não é suficiente fazer bem feito, é preciso mostrar o bem que realizamos. Saibas que estas imagens têm valor jurídico se forem assinadas com Certificado Digital, e podem ser valioso elemento de prova em caso de demanda judicial.

\section{3) Quais os horizontes da aplicação da In- formática na clínica odontológica? Como será o consultório do futuro? Ricardo Nakama}

Para todos os lados que olharmos encontramos o computador presente. Assim, no futuro próximo o computador estará em todos os consultórios, com agenda de horário, ficha clínica, administração em geral... Será o suporte de todas as nossas atividades clínicas e administrativas. Antevejo que as comunicações com o paciente serão através da internet. Tudo será falado de viva voz e, posteriormente, remetido pela internet, com Certificado Digital, e pedido de confirmação do recebimento. Ao invés de passar-lhes informações em papel, que carecem da assinatura do paciente concordando e nos obrigando a guardar estes papéis, teremos tudo digital, facilmente armazenado e encontrado, possibilitando múltiplas cópias idênticas, sem custo, a qualquer hora. É um sonho que se realiza. Mensagem pelo correio com o sistema AR será coisa do passado. Mais garantia nos dá a mensagem autenticada. Remarcação de consultas, registro de falhas na freqüência de visitas, registro de descuido com a escovagem, com o uso de gomas, tudo ficará documentado, com valor legal, se for remetido pela internet, com Certificado Digital. E isto será feito sem constrangimento, como um procedimento natural de confirmação. O paciente até vai gostar e vai valorizar a nossa sistemática. Ao contrário de quando the damos uma cópia de receita etc. etc. e the pedimos que assine e declare que recebeu o original de igual teor, o que é legalmente necessário.

\section{Adilson Luiz Ramos}

- Professor da Universidade Estadual de Maringá - UEM. - Coordenador do Curso de Pós-Graduação em Ortodontia e Ortopedia Facial - Especialização Latu sensu, promovido pela Associação Maringaense de Odontologia (regional ABO - Maringá).

- Mestre e Doutro em Ortodontia.

\section{Kurt Faltin Júnior}

- Pós-graduado em Ortopedia Maxilar pela Universidade de Bonn - Alemanha.

- Doutorado (Dr. Medicina Dentística) em Ortopedia pela Universidade de Bonn - Alemanha.

- Professor Titular da disciplina de Ortodontia da UNIP.

- Presidente da Associação Brasileira de Ortodontia.

\section{Ricardo Nakama \\ - Mestre - especialista em Ortodontia e Ortopedia Facial. \\ - Doutor em Ortodontia e Ortopedia Facial pela Uni- versidade Estadual Paulista Unesp/Araraquara.}

